\title{
Trade, Diplomacy, and Warfare: The Quest for Elite Rhizobia Inoculant Strains
}

\author{
Alice Checcucci, George C. DiCenzo, Marco Bazzicalupo and Alessio Mengoni* \\ Department of Biology, University of Florence, Florence, Italy
}

Rhizobia form symbiotic nitrogen-fixing nodules on leguminous plants, which provides an important source of fixed nitrogen input into the soil ecosystem. The improvement of symbiotic nitrogen fixation is one of the main challenges facing agriculture research. Doing so will reduce the usage of chemical nitrogen fertilizer, contributing to the development of sustainable agriculture practices to deal with the increasing global human population. Sociomicrobiological studies of rhizobia have become a model for the study of the evolution of mutualistic interactions. The exploitation of the wide range of social interactions rhizobia establish among themselves, with the soil and root microbiota, and with the host plant, could constitute a great advantage in the development of a new generation of highly effective rhizobia inoculants. Here, we provide a brief overview of the current knowledge on three main aspects of rhizobia interaction: trade of fixed nitrogen with the plant; diplomacy in terms of communication and possible synergistic effects; and warfare, as antagonism and plant control over symbiosis. Then, we propose new areas of investigation and the selection of strains based on the combination of the genetic determinants for the relevant rhizobia symbiotic behavioral phenotypes.

Keywords: sociomicrobiology, symbiosis, sustainable agriculture, nitrogen-fixation, bacterial genomics

\section{RHIZOBIA AS A MODEL FOR SOCIOMICROBIOLOGISTS}

Microorganisms have become popular models for addressing sociobiological questions related to the evolution of multicellularity, communication, and to the exchange of nutrients. Indeed, microbial systems are suitable for the study of mutualistic interactions due to their readiness of manipulation, their short generation times, and the simple methods for tracking of resources (West et al., 2006). Moreover, the social behaviors of microorganisms (e.g., cell-cell communication) have profound impacts on human health. In particular, cell-cell communication has been extensively studied with the aim of developing new antimicrobial strategies that block the social organization of pathogenic microorganisms, such as biofilm formation (Xavier, 2016).

Plant-associated bacteria, and more specifically rhizobia, have gained the attention of sociomicrobiologists thanks to the exchange of goods they experience with their host plant (West et al., 2002; Denison et al., 2003; Gubry-Rangin et al., 2010). Rhizobia are a polyphyletic group of Proteobacteria, with all rhizobia identified to date belonging to two proteobacterial classes: Alphaproteobacteria and Betaproteobacteria. Rhizobia live as free bacteria in soil or plants (as commensal endophytes), and may form symbiotic nitrogen fixing associations with compatible and 
leguminous plants. Fabaceae (Leguminosae) is the third largest family of Angiosperms and includes more than 20,000 species (Lewis, 2005). Access to nitrogen through the symbiosis is an important part of the evolutionary success of legumes, which are able to colonize a multitude of ecosystems and has led to expanded diversity. Moreover, symbiotic nitrogen fixation contributes to legumes being the second most important family of crop plants after the Poaceae; they account for $27 \%$ of world grain crop production and contribute up to $33 \%$ of the protein in the human diet (Smýkal et al., 2015).

The high economical relevance of the symbiotic interaction has promoted the production of commercial rhizobia inoculants. Inoculation of leguminous crops with rhizobia strains is known to considerably increase crop yield, mediated largely through symbiotic nitrogen fixation (Lupwayi et al., 2006). Soybean in Europe and South America, as well as several legumes in Australia, are probably the most emblematic examples (Thilakarathna and Raizada, 2017). Rhizobia inoculants also influence the overall rhizosphere microbiome, which may lead to biostimulation of other non-legume crops and can inhibit the growth of opportunistic bacterial pathogens (Trabelsi et al., 2011, 2012; Das et al., 2017). Moreover, rhizobia are ubiquitous in soil and in association with plants. Indeed, they can be viewed as plant-associated bacteria that colonize both legumes and nonleguminous plants (Mengoni et al., 2013). Several authors have found rhizobia in the endosphere and rhizosphere of cereals, such as rice [see for instance (Tan et al., 2001; Yanni et al., 2001)] and showed that rhizobia can promote plant growth in these nonlegumes species (Bashan et al., 2014; Gopalakrishnan et al., 2015). In sum, rhizobia are important elements of an upcoming new green revolution, where plant-associated microorganisms are key players of eco(nomical) and eco(logical) crop yield increases, both as a direct source of fixed nitrogen in the agroecosystem, as well as through acting as promoters of plant growth and plant health.

During symbiotic interaction, the rhizobia induce the formation of specialized plant structures, known as nodules (Sprent et al., 2017), where nitrogen fixation takes place. Rhizobia provide the plant with fixed nitrogen in the form of ammonia, while the plant provides the rhizobia a homeostatic environment to undergo heterotrophic multiplication using carbon derived from photosynthates and additional micronutrients (e.g., Fe, $\mathrm{S}, \mathrm{Mo}$, etc.). Due to this exchange of nutrients, rhizobia have gained attention in sociomicrobiological studies as a model of the evolution of mutualistic interaction. In particular, Hamilton's rule [for a recent discussion see (Van Veelen et al., 2017)] has been investigated with respect to the exchange of goods taking place between rhizobia and plants (Kiers and Denison, 2008). In fact, by supplying its host with fixed nitrogen, rhizobia strains enhance host growth, thereby potentially increasing its access to photosynthates. However, several rhizobia strains can inhabit nodules found on the same host plant, even co-inhabiting the same nodule (Checcucci et al., 2016). This means that a nitrogenfixing rhizobia benefits not only its own kin, but also other rhizobia (and non-rhizobia) strains. Those strains compete for host resources and future nodulation opportunities, which paves the way for cheating to occur. However, it has been shown that plants sanction nodules that are inefficient at fixing nitrogen, providing a direct advantage (in the nodule endosphere) only for the mutualistic rhizobia (Kiers et al., 2003).

When considering the molecular mechanisms of social interactions among bacteria, and between plants and bacteria, a plethora of systems can be included, spanning from quorum sensing to volatile molecules, to the classical Nod Factors and flavonoids, to plant immunity cascades and NCR peptides (Mergaert et al., 2006; Van de Velde et al., 2010; Mine et al., 2014; Schulz-Bohm et al., 2015; Kai et al., 2016; Cao et al., 2017). In the last years, studies on competition for nodule occupancy by rhizobia have highlighted the role of several components [for a review see (Onishchuk et al., 2017)]. Here, we divide such components into systems for trade, diplomacy, and warfare. This of course should be considered as an approximation, as in the real global economy, trade and politics have tight and, in some case, combined roles in the same affair.

\section{TRADE}

Keeping on the parallelism between mutualistic interaction and biological markets (Werner et al., 2014), the collaborative behavior established by rhizobia and legumes can be compared to a trading partnership. The main good of exchange is fixed nitrogen, passed from bacteroids to the plant cell. In return, the rhizobia are compensated by the plant with space for growth (the nodule) and carbon compounds for the heterotrophic metabolism of the bacteroid. Nodule colonization by rhizobia indeed could be a high remunerative reward offered by the plant. However, the number of rhizobia released back to the soil from dehiscent nodules depends on the type of nodule [indeterminate and determinate, where bacteroids are terminally differentiated or not, respectively (Denison and Kiers, 2004a)], questioning if we can consider legume-rhizobial partnership a full mutualistic interaction (Cao et al., 2017).

Determining the exchange of metabolites (Prell and Poole, 2006; Udvardi and Poole, 2013), and measuring the relative costs invested by the plant and the bacterium during the symbiosis, is necessary to define a predictive model of the metabolic (trade) advantages of symbiotic nitrogen fixation. This model will not be trivial since symbiotic nitrogen fixation is a developmental process. Various cellular metabolites change in relation to the developmental zone of the nodule (White et al., 2007; Ogden et al., 2017). Consequently, the exchange of goods may be related to several biosynthetic and catabolic pathways. Finally, we have to keep in mind that, as large rhizobia genomes provide a high level of metabolic redundancy (diCenzo and Finan, 2015), the (horizontally transferred) dispensable genome fraction may promote considerable strain-specific metabolic variation. Such variability may imply a corresponding variation in the exchange of goods between the plant and rhizobia cells (Remigi et al., 2016). A main point going forward is to better understand this variability in order to select those rhizobia strains more effective in "rewarding" the plant (through the fixed nitrogen offered to the plant) for use as elite inoculants. 


\section{DIPLOMACY}

Aside from the classical exchange of benefits and the reciprocal control of the fitness (trade), the rhizobia-plant mutualism evolved the capacity for partner discrimination. Molecularly, the "entry visa" is based on the lipochitooligosaccharide molecule known as Nod Factor (NF) and NF receptors (Cao et al., 2017). Depending on their particular set of nod genes, different rhizobia produce structurally distinguishable NFs that establish the first line of partner choice (Geurts and Bisseling, 2002). However, nod genes are not particularly relevant in the selection of elite rhizobia bioinoculants, as they primarily dictate whether a strain can nodulate a specific legume but contribute little to the efficiency of nodulation.

Instead, the most relevant "diplomacy" genes for selection of elite bioinoculants strains with high competitiveness for nodule occupancy are, in principle, genes related to the modulation of communication and to the direct positive and negative interaction between the plant and bacterium (Figure 1). Among the most studied examples is the apparatus involved in quorum sensing. This apparatus is related to phytohormone modulating genes, such as those for auxin production and ACC deaminase that are potentially related to modulation of the rhizobialegume interaction ( $\mathrm{Ma}$ et al., 2004; Okazaki et al., 2004; Sugawara et al., 2006; Bianco and Defez, 2009; Checcucci et al., 2017). Additionally, quorum sensing in rhizobia is also linked to the transfer of symbiotic plasmids in several strains, including Rhizobium leguminosarum bv. viciae, Sinorhizobium fredii NGR234, and Sinorhizobium meliloti Rm41 [for a review see (Sanchez-Contreras et al., 2007)]. Interestingly, while the quorum sensing apparatus is present in several rhizobia species (González and Marketon, 2003), individual strains may show different responses to quorum sensing signaling molecules (SanchezContreras et al., 2007). This can be related to the large variability in the quorum sensing regulons of rhizobia (Galardini et al., 2015a). It is important to note that symbiotic nitrogen fixation abilities are uncoupled from colonization and nodulation abilities (Westhoek et al., 2017); i.e., rhizobia strains highly competitive for nodule occupancy do not necessarily fix nitrogen efficiently. This has resulted in the evolution of plant imposed sanctions toward ineffective nodules that do not fix nitrogen (Kiers et al., 2003, 2006; Denison and Kiers, 2004b; Kiers and Denison, 2008); otherwise, cheaters (non-mutualist strains) could possibly outcompete the mutualist ones (Gubry-Rangin et al., 2010; Checcucci et al., 2016; Westhoek et al., 2017).

Given that nodulation and nitrogen fixation abilities are not intrinsically linked, it will be necessary to separately consider both processes in the development of elite rhizobia bioinoculants. The exploration of the cornucopia of signaling pathways and of their role in determining the competitive abilities of strains, as well as their effect over the whole rhizosphere microbiome, will probably be one of the greatest challenges of the future. Signaling is mediated at many levels and in many ways, i.e., as cell-cell interaction, diffusible molecules, and possibly by other still poorly known or unknown mechanisms (i.e., volatile organic compounds, electric signals). Moreover, signaling is strongly dependant on the context where strains are growing, and can be influenced by co-resident microbes. Thus signaling cannot be fully examined using conventional microbiological investigations based on pure culture. Reconstructed root microbiotas and easy-to-use gene reporter systems coupled with genome-wide assessments of transcriptional activation during the various stages of symbiosis (Karunakaran et al., 2005; Gao and Teplitski, 2008; Pini et al., 2017) could be a strategy to help define the "diplomatic" relationships of rhizobia strains and the ways to exploit them for elite rhizobia strain selection.

\section{WARFARE}

In order for rhizobia to enter into a symbiotic nitrogen fixing relationship with a host plant, they have to effectively compete for rhizosphere colonization with other rhizobia and non-rhizobia. From the bacterial point of view, competition implies preventing the colonization of the niche by other strains. This can take two forms: exploitative (indirect), and interference (direct). Exploitative competition involves more effectively utilizing a common limiting nutrient. As examples, rhizobia can produce siderophores that sequester all available iron for use by themselves, limiting the ability of competitors to grow (diCenzo et al., 2014), or strains can better exploit specific carbon sources present in root exudates (Gage and Long, 1998; Ramachandran et al., 2011). Interference competition, which we refer to as "warfare," occurs when one cell directly prevents another cell from growing/surviving in the environment. This can occur, for example, through the production of antibacterial compounds, such as bacteriocins, that may play a still poorly defined role in the antagonistic interactions taking place during competition for nodule occupancy (Hirsch, 1979; Oresnik et al., 1999). Bacteriocin-encoding gene clusters can be found in many rhizobial genomes. A search of the IMG database (on August 7 , 2017) reported the presence of 11 annotated bacteriocinrelated proteins within the members of the genus Sinorhizobium (out of 61 genomes, from 1 to 3 per genome), spanning from bacteriocin transporter genes to bacteriocin protection genes. We hypothesize that such bacteriocins may promote antagonistic interactions among members of the same species both in the rhizosphere and within the nodule.

In several host species (e.g., members of the InvertedRepeat Lacking Clade that includes the majority of agriculturally relevant legumes), plant-rhizobia interaction involves the tight control of bacterial cell proliferation and differentiation based on antimicrobial peptides [nodule cysteine-rich peptides (NCRs)], as well as the suppression of the host immune response mediated through NF (Cao et al., 2017). The evolution of NCR peptides resulted in the emergence of some antagonistic, warfare-like features to the plant-rhizobia interaction. In the classical sense, NCR peptides do not represent warfare, and are perhaps better considered in a "policing" analogy as the "handcuffs" that capture the bacteria within the nodule. Nevertheless, NCR peptides fall into our somewhat broad definition of warfare as they represent a method used by the plant to prevent the bacterium from replicating. NCR peptides promote terminal differentiation of the rhizobia in the nodule, likely increasing the efficiency of nitrogen 


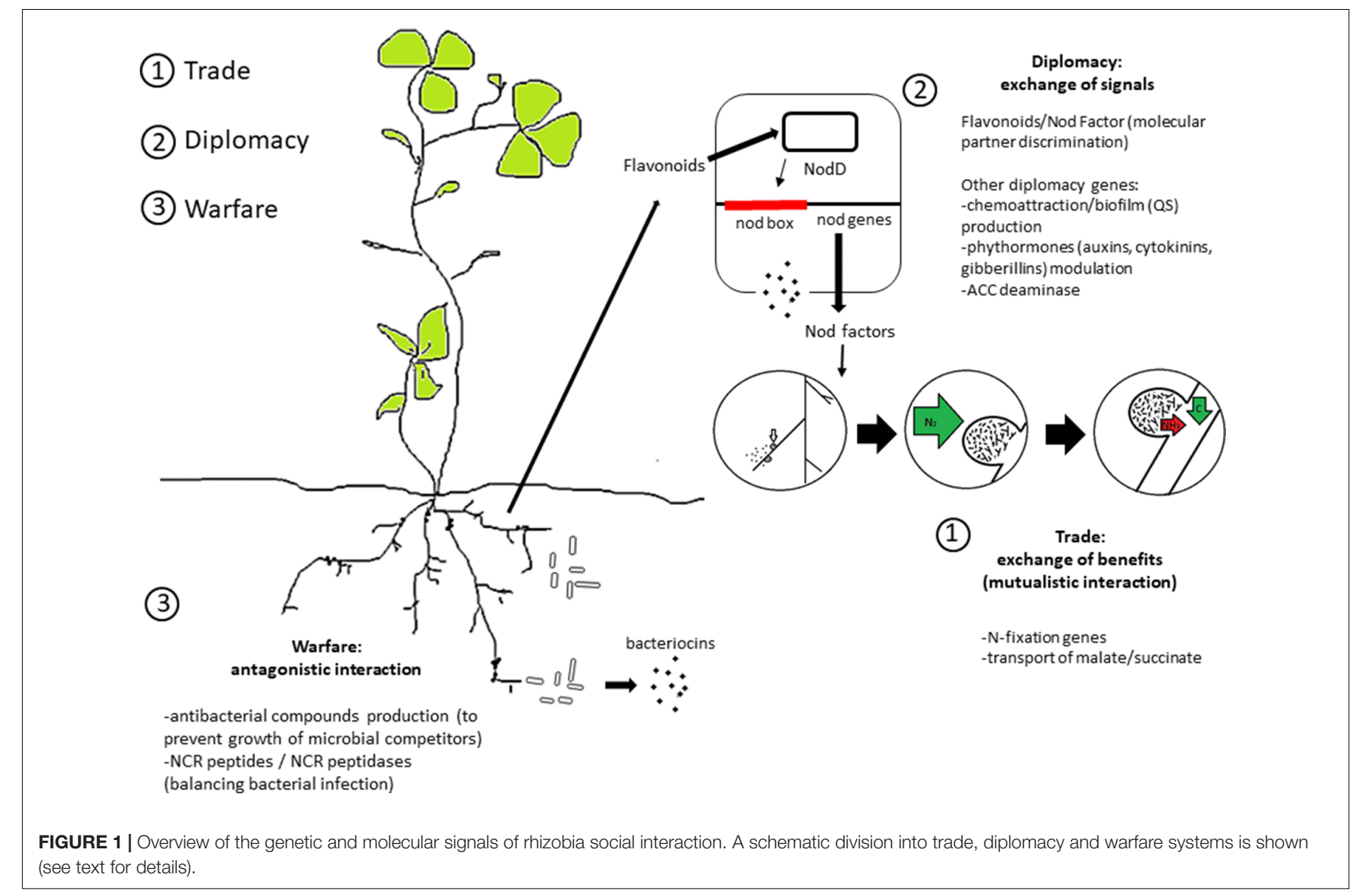

fixation but preventing the bacterium from ever living as a free-living microbe (increased plant fitness, decreased bacterium fitness). However, on the other hand, rhizobia have evolved NCR peptidases that can cleave NCR peptides, preventing terminal differentiation and nitrogen fixation, but promoting improved bacterial nodule colonization (decreased plant fitness, increased bacterium fitness). Recently, NCR peptidases were found to be involved in determining rhizobia - host compatibility (Price et al., 2015; Wang et al., 2017a,b; Yang et al., 2017). Interestingly, the genes encoding NCR peptidases are harbored by plasmids (Crook et al., 2012), which can be horizontally transmitted and are part of the dispensable genome fraction. This allows for the determination of partner compatibility at the level of a single strain, providing additional complexity to the variability of symbiotic and nitrogen-fixation abilities of possible inoculant strains.

\section{A SOCIOMICROBIOLOGY AND GENOMICS ASSISTED QUEST FOR ELITE INOCULANT STRAINS}

Whereas crop breeding is used to develop new plant cultivars with the desired features, very few research efforts have been dedicated to the development of ad hoc rhizobia inoculant strains (Catroux et al., 2001; Sessitsch et al., 2002). There are only a few strains currently used as seed inoculants. They have been selected (when known) on the basis of trials that showed increased crop yield. However, these studies included only a few plant cultivars and few pedo-climatic conditions (Denton et al., 2003). Variables such as plant cultivar, soil pedo-climatic conditions, and more specifically, variables related to the social interaction of rhizobia, have been only cursorily considered.

Elite rhizobia bioinoculants must effectively compete with the native rhizobia for nodule occupancy. This involves appropriately interacting with the soil and rhizosphere microbiomes, and surviving in the soil sufficiently long to interact with the plant. The elite strains should also be highly effective at providing the plant with fixed nitrogen. However, they should also combine a subset of other important, growth-promoting abilities. These could include, for example, producing auxin that can improve legume and non-legume growth, protecting the plant from pathogens, or being able to cope with drought, salt, pollutants, and/or acidic stress conditions. Moreover, but certainly not less important, the elite strain should be amenable to production by industrial fermentation, and stay viable on coated and inoculated seeds as well as in liquid or grain formulations. Finally, the inoculant could have limited year-to-year persistence in unplanted soil, to guarantee the possibility of applying newly improved strains each year without concern of competition from the previous year's inoculant. 
We would argue that taking into account a sociomicrobiology perspective is a necessity to ensure success in the engineering of rhizobia inoculants. This view is re-enforced when considering the effect of the native rhizobia population on the success of rhizobia bio-inoculants. The success of rhizobia inoculants in the cases cited above was partially due to the absence of an established symbiotic rhizobial populations (Deaker et al., 2004). However, for most crops, an indigenous rhizobia can limit, or completely abolish the positive effects of the inoculant [for a review see (Dwivedi et al., 2015)]. This is especially true if the indigenous rhizobia are highly competitive for nodule occupancy but with low nitrogen fixing abilities. Because of this, the competitiveness of rhizobia strains is one of the key aspects that should be considered when inoculant formulations are developed (Lupwayi et al., 2006).

Going forward, attention should be paid to all aspects of the social interactions that rhizobia strains have with the indigenous rhizobia and non-rhizobia rhizosphere population. As reported in the previous sections, social behaviors span from the efficiency of metabolite exchange with the plant, to interactions with the rhizosphere microbiota and access to the nodule endosphere, to the antagonism toward other strains or species, to the modulation of differentiation operated by NCR peptides. Most, if not all, such rhizobia behavioral phenotypes are ideal candidates for the selection of the most appropriate panel of strains to be used as inoculants in agriculture. The knowledge we currently have on the genetic determinants for some of these phenotypes may already permit the ad hoc design or selection of improved inoculant strains. Moreover, from an evolutionary point of view, rhizobia present a fascinating panorama to be explored to better understand such social behaviors and the mechanisms that maintain this high diversity of social-related phenotypes, such as selective pressure, drift, and genetic exchange.

The genomes of rhizobia are extremely variable (Maclean et al., 2007), and among species they span from the single large chromosome of $\sim 9 \mathrm{Mb}$ of the bradyrhizobia, to the highly multipartite genomes of the Rhizobium and Sinorhizobium genera that include several accessory replicons such as chromids, megaplasmids, and smaller plasmids (Galibert et al., 2001; Tian et al., 2012). Rhizobia also have large pangenomes, with a considerable portion of their genome consisting of accessory and dispensable genes (Tian et al., 2012; Galardini et al., 2015b; Young, 2016). For rhizobia with multipartite genomes, a functional modularity of the genome has been shown (Galardini et al., 2013, 2015a; diCenzo et al., 2016). Additionally, the secondary replicons are generally more genetically diverse between strains than the primary chromosome (Galardini et al.,

\section{REFERENCES}

Agnoli, K., Freitag, R., Gomes, M. C., Jenul, C., Suppiger, A., Mannweiler, O., et al. (2017). Use of synthetic hybrid strains to determine the role of replicon 3 in virulence of the Burkholderia cepacia complex. Appl. Environ. Microbiol. 83, e461-e417. doi: 10.1128/AEM.00461-17

Bashan, Y., De-Bashan, L. E., Prabhu, S. R., and Hernandez, J. P. (2014). Advances in plant growth-promoting bacterial inoculant technology: formulations and
2013). These properties can, in theory, permit the construction of "hybrid" strains by combining accessory replicons that harbor gene functions related to competition, symbiotic efficiency, and possibly tolerance to harsh soil conditions, from different donor strains in a single genome. This would be similar to the approach recently employed by Agnoli et al. (2017) with Burkholderia cepacia complex species. Additionally, the large pangenomes may harbor many genes related to the important "social" phenotypes referred in the previous paragraphs. Such "social" genes may be useful candidates for strain improvement and may be combined together (in a single strain) by shuffling secondary replicons from different donors. We can imagine the development of an approach to promote horizontal gene transfer of such genetic determinants between strains in a sort of "pangenomeassisted selection," conceptually analogous to the marker-assisted selection in crops (Collard and Mackill, 2008). In this process, we could choose (select) from the pangenomic space of a given rhizobial species those genes that can, once combined in a single strain, provide the elite features. However, to efficiently deal with "pangenome-assisted selection," new experimental settings and knowledge are compulsory to (i) perform high throughput screenings of the symbiotic potential of rhizobial strains, and (ii) have detailed information about the signaling between rhizobia, the plant, and the rhizosphere microbiota. Experiments aimed at deciphering the exchange of signals and the effect on plant growth in reconstructed root microbiotas are needed to move toward a more comprehensive view of the intimate sociobiological relationship between the plant and its rhizobial partners, and then promote a rationale selection of elite rhizobial inoculants.

\section{AUTHOR CONTRIBUTIONS}

AM conceived the study. AC drafted the manuscript. GD and MB contributed discussing the ideas and contributed in drafting the manuscript. All authors read and approved the final version of the manuscript.

\section{FUNDING}

This work was supported by the University of Florence, project "Dinamiche dell'evoluzione dei genomi batterici: l'evoluzione del genoma multipartito e la suddivisione in moduli funzionali," call "PROGETTI STRATEGICI DI ATENEO ANNO 2014" to AM. GD was supported by the Natural Sciences and Engineering Research Council of Canada through a PDF fellowship.

practical perspectives (1998-2013). Plant Soil 378, 1-33. doi: 10.1007/s11104013-1956-x

Bianco, C., and Defez, R. (2009). Medicago truncatula improves salt tolerance when nodulated by an indole-3-acetic acid-overproducing Sinorhizobium meliloti strain. J. Exp. Bot. 60, 3097-3107. doi: 10.1093/jxb/erp140

Cao, Y., Halane, M. K., Gassmann, W., and Stacey, G. (2017). The role of plant innate immunity in the legume-rhizobium symbiosis. Annu. Rev. Plant Biol. 68, 535-561. doi: 10.1146/annurev-arplant-042916-041030 
Catroux, G., Hartmann, A., and Revellin, C. (2001). Trends in rhizobial inoculant production and use. Plant Soil 230, 21-30. doi: 10.1023/A:1004777115628

Checcucci, A., Azzarello, E., Bazzicalupo, M., De Carlo, A., Emiliani, G., Mancuso, S., et al. (2017). Role and regulation of ACC deaminase gene in Sinorhizobium meliloti: Is it a symbiotic, rhizospheric or endophytic gene? Front. Genet. 8:6. doi: 10.3389/fgene.2017.00006

Checcucci, A., Azzarello, E., Bazzicalupo, M., Galardini, M., Lagomarsino, A., Mancuso, S., et al. (2016). Mixed nodule infection in Sinorhizobium melilotiMedicago sativa symbiosis suggest the presence of cheating behavior. Front. Plant Sci. 7:835. doi: 10.3389/fpls.2016.00835

Collard, B. C., and Mackill, D. J. (2008). Marker-assisted selection: an approach for precision plant breeding in the twenty-first century. Philos. Trans. R. Soc. Lond. B Biol. Sci. 363, 557-572. doi: 10.1098/rstb.2007.2170

Crook, M. B., Lindsay, D. P., Biggs, M. B., Bentley, J. S., Price, J. C., Clement, S. C., et al. (2012). Rhizobial plasmids that cause impaired symbiotic nitrogen fixation and enhanced host invasion. Mol. Plant Microbe Int. 25, 1026-1033. doi: 10.1094/MPMI-02-12-0052-R

Das, K., Prasanna, R., and Saxena, A. K. (2017). Rhizobia: a potential biocontrol agent for soilborne fungal pathogens. Folia Microbiol. doi: 10.1007/s12223-0170513-z [Epub ahead of print].

Deaker, R., Roughley, R. J., and Kennedy, I. R. (2004). Legume seed inoculation technology-a review. Soil Biol. Biochem. 36, 1275-1288. doi: 10.1016/j.soilbio. 2004.04.009

Denison, R. F., Bledsoe, C., Kahn, M., O'gara, F., Simms, E. L., and Thomashow, L. S. (2003). Cooperation in the rhizosphere and the "free rider" problem. Ecology 84, 838-845. doi: 10.1890/0012-9658(2003)084[0838:CITRAT] 2.0.CO;2

Denison, R. F., and Kiers, E. T. (2004a). Lifestyle alternatives for rhizobia: mutualism, parasitism, and forgoing symbiosis. FEMS Microbiol. Lett. 237, 187-193. doi: 10.1111/j.1574-6968.2004.tb09695.x

Denison, R. F., and Kiers, E. T. (2004b). Why are most rhizobia beneficial to their plant hosts, rather than parasitic? Microbes Infect 6, 1235-1239. doi: 10.1016/j. micinf.2004.08.005

Denton, M. D., Reeve, W. G., Howieson, J. G., and Coventry, D. R. (2003). Competitive abilities of common field isolates and a commercial strain of Rhizobium leguminosarum bv. trifolii for clover nodule occupancy. Soil Biol. Biochem. 35, 1039-1048. doi: 10.1016/S0038-0717(03)00146-9

diCenzo, G. C., Checcucci, A., Bazzicalupo, M., Mengoni, A., Viti, C., Dziewit, L., et al. (2016). Metabolic modelling reveals the specialization of secondary replicons for niche adaptation in Sinorhizobium meliloti. Nat. Commun. 7:12219. doi: 10.1038/ncomms12219

diCenzo, G. C., and Finan, T. M. (2015). Genetic redundancy is prevalent within the 6.7 Mb Sinorhizobium meliloti genome. Mol. Genet. Genomics 290, 1345-1356. doi: 10.1007/s00438-015-0998-6

diCenzo, G. C., Maclean, A. M., Milunovic, B., Golding, G. B., and Finan, T. M. (2014). Examination of prokaryotic multipartite genome evolution through experimental genome reduction. PLOS Genet. 10:e1004742. doi: 10. 1371/journal.pgen.1004742

Dwivedi, S. L., Sahrawat, K. L., Upadhyaya, H. D., Mengoni, A., Galardini, M., Bazzicalupo, M., et al. (2015). Advances in host plant and rhizobium genomics to enhance symbiotic nitrogen fixation in grain legumes. Adv. Agron. 129, 1-116. doi: 10.1016/bs.agron.2014.09.001

Gage, D. J., and Long, S. R. (1998). $\alpha$-Galactoside uptake in Rhizobium meliloti: isolation and characterization of agpA, a gene encoding a periplasmic binding protein required for melibiose and raffinose utilization. J. Bacteriol. 180, 5739-5748.

Galardini, M., Brilli, M., Spini, G., Rossi, M., Roncaglia, B., Bani, A., et al. (2015a). Evolution of intra-specific regulatory networks in a multipartite bacterial genome. PLOS Comput. Biol. 11:e1004478. doi: 10.1371/journal.pcbi. 1004478

Galardini, M., Pini, F., Bazzicalupo, M., Biondi, E. G., and Mengoni, A. (2015b). "Pangenome evolution in the symbiotic nitrogen fixer Sinorhizobium meliloti," in Biological Nitrogen Fixation, ed. F. J. de Bruijn (New York, NY: John Wiley \& Sons, Inc), 265-270. doi: 10.1002/9781119053095.ch26

Galardini, M., Pini, F., Bazzicalupo, M., Biondi, E. G., and Mengoni, A. (2013). Replicon-dependent bacterial genome evolution: the case of Sinorhizobium meliloti. Genome Biol. Evol. 5, 542-558. doi: 10.1093/gbe/evt027
Galibert, F., Finan, T. M., Long, S. R., Puhler, A., Abola, P., Ampe, F., et al. (2001). The composite genome of the legume symbiont Sinorhizobium meliloti. Science 293, 668-672. doi: 10.1126/science.1060966

Gao, M., and Teplitski, M. (2008). RIVET-a tool for in vivo analysis of symbiotically relevant gene expression in Sinorhizobium meliloti. Mol. Plant Microbe Interact. 21, 162-170. doi: 10.1094/MPMI-21-2-0162

Geurts, R., and Bisseling, T. (2002). Rhizobium Nod factor perception and signalling. Plant Cell 14, S239-S249. doi: 10.1105/tpc.002451

González, J. E., and Marketon, M. M. (2003). Quorum sensing in nitrogen-fixing rhizobia. Microbiol. Mol. Biol. Rev. 67, 574-592. doi: 10.1128/MMBR.67.4.574592.2003

Gopalakrishnan, S., Sathya, A., Vijayabharathi, R., Varshney, R. K., Gowda, C. L. L., and Krishnamurthy, L. (2015). Plant growth promoting rhizobia: challenges and opportunities. 3 Biotech 5, 355-377. doi: 10.1007/s13205-014-0241-x

Gubry-Rangin, C., Garcia, M., and Béna, G. (2010). Partner choice in Medicago truncatula-Sinorhizobium symbiosis. Proc. Biol. Sci. 277, 1947-1951. doi: 10. 1098/rspb.2009.2072

Hirsch, P. R. (1979). Plasmid-determined bacteriocin production by Rhizobium leguminosarum. Microbiology 113, 219-228. doi: 10.1099/00221287-113-2-219

Kai, M., Effmert, U., and Piechulla, B. (2016). Bacterial-plant-interactions: approaches to unravel the biological function of bacterial volatiles in the rhizosphere. Front. Microbiol. 7:108. doi: 10.3389/fmicb.2016.00108

Karunakaran, R., Mauchline, T. H., Hosie, A. H. F., and Poole, P. S. (2005). A family of promoter probe vectors incorporating autofluorescent and chromogenic reporter proteins for studying gene expression in Gram-negative bacteria. Microbiology 151, 3249-3256. doi: 10.1099/mic.0.28311-0

Kiers, E. T., and Denison, R. F. (2008). Sanctions, cooperation, and the stability of plant-rhizosphere mutualisms. Annu. Rev. Ecol. Evol. Syst. 39, 215-236. doi: 10.1146/annurev.ecolsys.39.110707.173423

Kiers, E. T., Rousseau, R. A., and Denison, R. F. (2006). Measured sanctions: legume hosts detect quantitative variation in rhizobium cooperation and punish accordingly. Evol. Ecol. Res. 8, 1077-1086.

Kiers, E. T., Rousseau, R. A., West, S. A., and Denison, R. F. (2003). Host sanctions and the legume-rhizobium mutualism. Nature 425, 78-81. doi: 10 . 1038/nature01931

Lewis, G. P. (2005). Legumes of the World. Richmond: Royal Botanic Gardens Kew. Lupwayi, N. Z., Clayton, G. W., and Rice, W. A. (2006). Rhizobial inoculants for legume crops. J. Crop Improv. 15, 289-321. doi: 10.1300/J411v15n02_09

Ma, W., Charles, T. C., and Glick, B. R. (2004). Expression of an exogenous 1aminocyclopropane-1-carboxylate deaminase gene in Sinorhizobium meliloti increases its ability to nodulate alfalfa. Appl. Environ. Microbiol. 70, 5891-5897. doi: 10.1128/AEM.70.10.5891-5897.2004

Maclean, A. M., Finan, T. M., and Sadowsky, M. J. (2007). Genomes of the symbiotic nitrogen-fixing bacteria of legumes. Plant Physiol. 144, 615-622. doi: 10.1104/pp.107.101634

Mengoni, A., Bazzicalupo, M., Giuntini, E., Pini, F., and Biondi, E. G. (2013). "Genomic and functional diversity of the sinorhizobial model group," in Symbiotic Endophytes, ed. R. Aroca (Berlin: Springer-Verlag), 69-85. doi: 10. 1007/978-3-642-39317-4_4

Mergaert, P., Uchiumi, T., Alunni, B., Evanno, G., Cheron, A., Catrice, O., et al. (2006). Eukaryotic control on bacterial cell cycle and differentiation in the Rhizobium-legume symbiosis. Proc. Natl. Acad. Sci. U.S.A. 103, 5230-5235. doi: 10.1073/pnas.0600912103

Mine, A., Sato, M., and Tsuda, K. (2014). Toward a systems understanding of plant-microbe interactions. Front. Plant Sci. 5:423. doi: 10.3389/fpls.2014. 00423

Ogden, A. J., Gargouri, M., Park, J., Gang, D. R., and Kahn, L. (2017). Integrated analysis of zone-specific protein and metabolite profiles within nitrogen-fixing Medicago truncatula-Sinorhizobium medicae nodules. PLOS ONE 12:e0180894. doi: 10.1371/journal.pone.0180894

Okazaki, S., Nukui, N., Sugawara, M., and Minamisawa, K. (2004). Rhizobial strategies to enhance symbiotic interactions: rhizobitoxine and 1aminocyclopropane-1-carboxylate deaminase. Microbes Environ. 19, 99-111. doi: $10.1264 /$ jsme2.19.99

Onishchuk, O. P., Vorobyov, N. I., and Provorov, N. A. (2017). Nodulation competitiveness of nodule bacteria: genetic control and adaptive significance. Appl. Biochem. Biotechnol. 53, 131-139. doi: 10.1134/S0003683817020132 
Oresnik, I. J., Twelker, S., and Hynes, M. F. (1999). Cloning and characterization of a Rhizobium leguminosarum gene encoding a bacteriocin with similarities to RTX toxins. Appl. Environ. Microbiol. 65, 2833-2840.

Pini, F., East, A. K., Appia-Ayme, C., Tomek, J., Karunakaran, R., MendozaSuarez, M., et al. (2017). Lux bacterial biosensors for in vivo spatiotemporal mapping of root secretion. Plant Physiol. 174, 1289-1306. doi: 10.1104/pp.16. 01302

Prell, J., and Poole, P. (2006). Metabolic changes of rhizobia in legume nodules. Trends Microbiol. 14, 161-168. doi: 10.1016/j.tim.2006.02.005

Price, P. A., Tanner, H. R., Dillon, B. A., Shabab, M., Walker, G. C., and Griffitts, J. S. (2015). Rhizobial peptidase HrrP cleaves host-encoded signaling peptides and mediates symbiotic compatibility. Proc. Natl. Acad. Sci. U.S.A. 112, 1524415249. doi: 10.1073/pnas.1417797112

Ramachandran, V. K., East, A. K., Karunakaran, R., Downie, J. A., and Poole, P. S. (2011). Adaptation of Rhizobium leguminosarum to pea, alfalfa and sugar beet rhizospheres investigated by comparative transcriptomics. Genome Biol. 12:R106. doi: 10.1186/gb-2011-12-10-r106

Remigi, P., Zhu, J., Young, J. P. W., and Masson-Boivin, C. (2016). Symbiosis within symbiosis: evolving nitrogen-fixing legume symbionts. Trends Microbiol. 24, 63-75. doi: 10.1016/j.tim.2015.10.007

Sanchez-Contreras, M., Bauer, W. D., Gao, M., Robinson, J. B., and Downie, J. A. (2007). Quorum-sensing regulation in rhizobia and its role in symbiotic interactions with legumes. Philos. Trans. R. Soc. Lond. B. Biol. Sci. 362, 1149-1163. doi: 10.1098/rstb.2007.2041

Schulz-Bohm, K., Zweers, H., De Boer, W., and Garbeva, P. (2015). A fragrant neighborhood: volatile mediated bacterial interactions in soil. Front. Microbiol. 6:1212. doi: 10.3389/fmicb.2015.01212

Sessitsch, A., Howieson, J., Perret, X., Antoun, H., and Martinez-Romero, E. (2002). Advances in Rhizobium research. Crit. Rev. Plant Sci. 21, 323-378. doi: 10.1080/ 0735-260291044278

Smýkal, P., Coyne, C. J., Ambrose, M. J., Maxted, N., Schaefer, H., Blair, M. W., et al. (2015). Legume crops phylogeny and genetic diversity for science and breeding. Crit. Rev. Plant Sci. 34, 43-104. doi: 10.1080/07352689.2014.897904

Sprent, J. I., Ardley, J., and James, E. K. (2017). Biogeography of nodulated legumes and their nitrogen-fixing symbionts. New Phytol. 215, 40-56. doi: 10.1111/nph. 14474

Sugawara, M., Okazaki, S., Nukui, N., Ezura, H., Mitsui, H., and Minamisawa, K. (2006). Rhizobitoxine modulates plant-microbe interactions by ethylene inhibition. Biotechnol. Adv. 24, 382-388. doi: 10.1016/j.biotechadv.2006.01.004

Tan, Z. Y., Hurek, T., Vinuesa, P., Muller, P., Ladha, J. K., and Reinhold-Hurek, B. (2001). Specific detection of Bradyrhizobium and Rhizobium strains colonizing rice (Oryza sativa) roots by $16 \mathrm{~S}-23 \mathrm{~S}$ ribosomal DNA intergenic spacer-targeted PCR. Appl. Environ. Microbiol. 67, 3655-3664. doi: 10.1128/AEM.67.8.36553664.2001

Thilakarathna, M. S., and Raizada, M. N. (2017). A meta-analysis of the effectiveness of diverse rhizobia inoculants on soybean traits under field conditions. Soil Biol. Biochem. 105, 177-196. doi: 10.1016/j.soilbio.2016.11.022

Tian, C. F., Zhou, Y. J., Zhang, Y. M., Li, Q. Q., Zhang, Y. Z., Li, D. F., et al. (2012). Comparative genomics of rhizobia nodulating soybean suggests extensive recruitment of lineage-specific genes in adaptations. Proc. Natl. Acad. Sci. U.S.A. 109, 8629-8634. doi: 10.1073/pnas.1120436109

Trabelsi, D., Ben Ammar, H., Mengoni, A., and Mhamdi, R. (2012). Appraisal of the crop-rotation effect of rhizobial inoculation on potato cropping systems in relation to soil bacterial communities. Soil Biol. Biochem. 54, 1-6. doi: 10.1016/ j.soilbio.2012.05.013

Trabelsi, D., Mengoni, A., Ben Ammar, H., and Mhamdi, R. (2011). Effect of on-field inoculation of Phaseolus vulgaris with rhizobia on soil bacterial communities. FEMS Microbiol. Ecol. 77, 211-222. doi: 10.1111/j.1574-6941. 2011.01102. $\mathrm{x}$

Udvardi, M., and Poole, P. S. (2013). Transport and metabolism in legume-rhizobia symbioses. Annu. Rev. Plant Biol. 68, 781-805. doi: 10.1146/annurev-arplant050312-120235

Van de Velde, W., Zehirov, G., Szatmari, A., Debreczeny, M., Ishihara, H., Kevei, Z., et al. (2010). Plant peptides govern terminal differentiation of bacteria in symbiosis. Science 327, 1122-1126. doi: 10.1126/science.1184057

Van Veelen, M., Allen, B., Hoffman, M., Simon, B., and Veller, C. (2017). Hamilton's rule. J. Theor. Biol. 414, 176-230. doi: 10.1016/j.jtbi.2016. 08.019

Wang, Q., Liu, J., Li, H., Yang, S., Körmöczi, P., Kereszt, A., et al. (2017a). Nodulespecific cysteine-rich peptides negatively regulate nitrogen-fixing symbiosis in a strain-specific manner in Medicago truncatula. Mol. Plant Microbe Interact. doi: 10.1094/MPMI-08-17-0207-R [Epub ahead of print].

Wang, Q., Yang, S., Liu, J., Terecskei, K., Ábrahám, E., Gombár, A., et al. (2017b). Host-secreted antimicrobial peptide enforces symbiotic selectivity in Medicago truncatula. Proc. Natl. Acad. Sci. U.S.A. 114, 6854-6859. doi: 10.1073/pnas. 1700715114

Werner, G. D. A., Strassmann, J. E., Ivens, A. B. F., Engelmoer, D. J. P., Verbruggen, E., Queller, D. C., et al. (2014). Evolution of microbial markets. Proc. Natl. Acad. Sci. U.S.A. 111, 1237-1244. doi: 10.1073/pnas.1315980111

West, S. A., Griffin, A. S., Gardner, A., and Diggle, S. P. (2006). Social evolution theory for microorganisms. Nat. Rev. Microbiol. 4, 597-607. doi: 10.1038/ nrmicro1461

West, S. A., Kiers, E. T., Simms, E. L., and Denison, R. F. (2002). Sanctions and mutualism stability: Why do rhizobia fix nitrogen? Philos. Trans. R. Soc. Lond. B Biol. Sci. 269, 685-694. doi: 10.1098/rspb.2001.1878

Westhoek, A., Field, E., Rehling, F., Mulley, G., Webb, I., Poole, P. S., et al. (2017). Policing the legume-Rhizobium symbiosis: a critical test of partner choice. Sci. Rep. 7:1419. doi: 10.1038/s41598-017-01634-2

White, J., Prell, J., James, E. K., and Poole, P. (2007). Nutrient sharing between symbionts. Plant Physiol. 144, 604-614. doi: 10.1104/pp.107.097741

Xavier, J. B. (2016). Sociomicrobiology and pathogenic bacteria. Microbiol. Spectr. 4, VMBF-0019-2015. doi: 10.1128/microbiolspec.VMBF-0019-2015

Yang, S., Wang, Q., Fedorova, E., Liu, J., Qin, Q., Zheng, Q., et al. (2017). Microsymbiont discrimination mediated by a host-secreted peptide in Medicago truncatula. Proc. Natl. Acad. Sci. U.S.A. 114, 6848-6853. doi: 10.1073/ pnas. 1700460114

Yanni, Y. G., Rizk, R. Y., Abd El-Fattah, F. K., Squartini, A., Corich, V., Giacomini, A., et al. (2001). The beneficial plant growth-promoting association of Rhizobium leguminosarum bv. trifolii with rice roots. Aust. J. Plant Physiol. 28, 845-870. doi: 10.1071/PP01069

Young, J. P. W. (2016). Bacteria are smartphones and mobile genes are apps. Trends Microbiol. 24, 931-932. doi: 10.1016/j.tim.2016.09.002

Conflict of Interest Statement: The authors declare that the research was conducted in the absence of any commercial or financial relationships that could be construed as a potential conflict of interest.

Copyright (C) 2017 Checcucci, DiCenzo, Bazzicalupo and Mengoni. This is an openaccess article distributed under the terms of the Creative Commons Attribution License (CC BY). The use, distribution or reproduction in other forums is permitted, provided the original author(s) or licensor are credited and that the original publication in this journal is cited, in accordance with accepted academic practice. No use, distribution or reproduction is permitted which does not comply with these terms. 